\title{
Risk Factors for Early Childhood Caries Based on Identification of Veillonella spp. Using RT-PCR
}

\author{
Asty Samiaty Setiawan ${ }^{1}$, Risqa Rina Darwita ${ }^{\circledR}$, Sri Susilawati ${ }^{1}$, Diah Ayu Maharani $^{\circledR}$, Ariadna \\ Adisattya Djais ${ }^{3}$
}

${ }^{1}$ Department of Community Dental Health, Faculty of Dentistry, University of Padjadjaran, Bandung, Indonesia.

2Department of Dental Health and Preventive Dentistry, Faculty of Dentistry, University of Indonesia, Jakarta, Indonesia.

${ }^{3}$ Department of Oral Biology, Faculty of Dentistry, University of Indonesia, Jakarta, Indonesia.

Author to whom correspondence should be addressed: Risqa Rina Darwita, Department of Dental Health and Preventive Dentistry, Faculty of Dentistry, University of Indonesia, Jakarta, 10430, Indonesia. Phone: 081298773359. E-mail: risqarina2004@yahoo.com.

Academic Editor: Alessandro Leite Cavalcanti

Received: 10 February 2020 / Accepted: 29 June 2020 / Published: 25 July 2020

How to cite this article: Setiawan AS, Darwita RR, Susilawati S, Maharani DA, Djais AA. Risk factors for early childhood caries based on identification of Veillonella spp. using RT-PCR. Pesqui Bras Odontopediatria Clín Integr. 2020; $20:$ e5701. https://doi.org/10.1590/pboci.2020.147

\begin{abstract}
Objective: To identify the occurrence of Veillonella spp. in children using real-time PCR (RT-PCR) and to determine its role as a risk factor for ECC in children aged 2-3 years. Material and Methods: A crosssectional survey was conducted and samples from 87 children aged 2-3 years, who lived in selected villages in the Bandung City area, Indonesia, were collected. Examination for dental caries was performed using standard checks for decay, missing, and filled surfaces (dfms), and saliva samples were taken. Microbiological examination was performed using RT-PCR with primers consisting of one primary set for Veillonella spp. and one universal primary set for $16 \mathrm{~S}$ rDNA. We performed statistical testing using the Mann Whitney rank-sum test. Results: A total of 87 children were sampled, and an ECC prevalence of $71.3 \%$ was found, with a mean dmfs of $7.1( \pm 9.1)$. The proportion of Veillonella spp. in caries-free children was $2.13 \pm 2.30$, while in children with ECC, it was $3.29 \pm 6.83$. Conclusion: The proportion of Veillonella spp. in children with ECC was higher than in caries-free children; therefore, Veillonella spp. may be a risk factor for ECC.
\end{abstract}

Keywords: Dental Caries; Gram-Negative Bacteria; Polymerase Chain Reaction. 


\section{Introduction}

The etiology of early childhood caries (ECC) is multifactorial and complex, involving environmental, behavioral, socioeconomic, and biological factors. ECC is dental caries characterized by infection with Streptococcus mutans, which sometimes comprises more than $30 \%$ of the flora of plaque biofilms [1]. S. mutans plays an important role in the etiology of ECC, and numerous studies have shown the importance of bacterial testing as a predictor when determining the risk of developing caries. The numbers of participants in these studies were relatively small, however, and the majority of researchers did not take into account any confounding factors, but the studies did provide enough evidence to suggest that the presence of $S$. mutans in the dental plaque or saliva of caries-free preschool children may be associated with a significant increase in the risk of developing caries [2,3].

The amount of $S$. mutans in plaque varies according to the development of dental caries. There may also be other microorganisms associated with the occurrence of dental caries [1]. Previous authors used $16 \mathrm{~S}$ rRNA gene sequencing and PCR to detect all species of bacteria that might be associated with caries in primary and permanent teeth, with participants in the range of 2 to 21 -years-old. The results revealed that $10 \%-20 \%$ of individuals with severe caries might not have a detectable amount of $S$. mutans but may have other acid-producing species [4]. In some carious lesions, S. mutans may comprise the smallest bacterial component in dental plaque. Other acid producing species such as Veillonella, Lactobacillus, Bifidobacterium, and Propionibacterium, which lower $\mathrm{pH}$, might play a significant role in caries incidence [5]. A longitudinal study should be performed to confirm whether $S$. mutans is indeed a risk factor for ECC [6]. Veillonella and Lactobacillus have been found in children with severe ECC [7].

Veillonella is a bacteria often found in individuals with severe early childhood caries (S-ECC); it does not have any acidogenic properties but is produced by various acidogenic species as a source for carbon that has the ability to promote cariogenic species' growth and survival [1]. The previous study has shown that an increase in Veillonella can occur in children with poor oral hygiene status [8]. The metabolism of S. mutans and Veillonella spp. can be considered as glucose and other sugars being converted into lactic acid by $S$. mutans, with Veillonella spp. subsequently metabolizing this lactic acid into a weaker acid, carbon dioxide, and hydrogen. The amount of lactic acid that can be produced is limited by the quantity of available carbohydrates, the growth rate of $S$. mutans and Veillonella spp., as well as the acidity of the environment. S. mutans has been extensively researched and was found to be the main cause of dental caries, whereas the relationship between $S$. mutans and Veillonella spp. metabolism has yet to be fully clarified, making these bacteria a useful pair for coevolution studies and to identify various ways to reduce the incidence of caries [9].

This study aimed to identify Veillonella spp. using real-time polymerase chain reaction (RT-PCR) and determine its role as a risk factor for ECC in children aged 2-3 years. A molecular method is more appropriate for identifying bacteria when studying the microbiota associated with dental caries. DNA sequence-based assays with $16 \mathrm{~S}$ ribosomal DNA (rDNA) sequence-based clonal analysis can be used to identify closely related species that are difficult to differentiate when using culture-based approaches [10].

\section{Material and Methods}

Study Design and Sample

A cross-sectional study was developed using samples from children aged 2-3 years living in selected villages with active Integrated Service Post (Posyandu) in the Bandung City Community Health Center (Puskesmas) of Sukajadi, according to predetermined population criteria. 
The sample selection was performed using non-probability sampling with a purposive sampling technique, with data collection carried out during March and April 2019. The sample size was determined based on total sample size according to the criteria of the predetermined population. The inclusion criteria were that a child should be in good health, have no systemic abnormalities, and be willing to have an oral examination. The exclusion criteria were children who had an abnormality in their mouth, such that they could not open their mouths or have been taking antibiotics for a long time.

\section{Clinical Examination}

Two trained examiners conducted a clinical examination of all children with the aid of World Health Organization Community Periodontal Index probes and disposable mouth mirrors. The children were examined for caries to provide baseline data; World Health Organization standard check forms were used to record decay, missing, and filled surfaces (dmfs) from occlusal, mesial, buccal, and distal primary teeth [11]. Cohen's Kappa was used to assess intra-examiner agreement of the assessments [12].

\section{Microbiological Examination}

Saliva samples were collected from beneath the tongue using a 1-mL needleless syringe (up to a maximum of $1 \mathrm{~mL}$ ); the saliva was then transferred to a $15 \mathrm{~mL}$ centrifuge tube. Saliva samples were stored in a refrigerator at $-20^{\circ} \mathrm{C}$ until use.

\section{DNA Extraction}

Prior to DNA extraction, stored saliva samples were thawed, transferred to $1.5 \mathrm{~mL}$ Eppendorf tubes, and centrifuged at 3,000 rpm for 10 minutes. Sterile water $(1 \mathrm{~mL})$ was added to the pellet in the $1.5 \mathrm{~mL}$ Eppendorf tube, which was vortexed then centrifuged at 10,000 to $20,000 \mathrm{rpm}$ for 10 minutes. The supernatants were removed and discarded instagene matrix that was placed on top of a magnetic stirrer was added to the colony as much as $200 \mu \mathrm{L}$. The Eppendorf tube was vortexed then placed in a $56^{\circ} \mathrm{C}$ water bath for 30 minutes. The pellet was then vortexed for 10 seconds, inserted into a thermoblock for 8 min, vortexed, and centrifuged at $10,000-20,000 \mathrm{rpm}$ for 3 minutes at $100^{\circ} \mathrm{C}$. The resulting supernatants were transferred into fresh $1.5 \mathrm{~mL}$ Eppendorf tubes and stored in a refrigerator at $4^{\circ} \mathrm{C}$.

\section{Quantification of DNA}

Quantitative and qualitative testing of the extracted DNA was performed to identify its concentration using Qubit Fluorometer and Qubit ds DNA BR Assay (Thermo Fisher Scientific, Waltham, MA, USA). Making a working solution for samples and a standard solution to calibrate Qubit Fluorometer from Qubit ds DNA BR Assay with a calculation of every sample containing $199 \mu \mathrm{L}$ Qubit buffer solution and $1 \mu \mathrm{L}$ reagent that was inserted into a $1.5 \mathrm{~mL}$ Eppendorf tube, vortexed, and spun down for $10 \mathrm{sec}$. The volume of the working solution was made according to the number of samples. The mixture was then added to a Qubit tube, where the standard solution consisted of $190 \mu \mathrm{L}$ working solution and $10 \mu \mathrm{L}$ standard solution I and II, while for the sample solution the tube contained $198 \mu \mathrm{L}$ working solution and $2 \mu \mathrm{L}$ of the sample that had undergone DNA extraction. The Qubit Fluorometer was calibrated using standard solutions I and II. Once calibration had been confirmed, the DNA concentration calculation could be performed. The sample solution in the Qubit tube was vortexed then inserted into the Qubit Fluorometer so that the concentration of DNA in each sample could be determined. 
Design of Primer Sets

The real-time PCR process needs a suitable primer for the bacteria under test. In this study, the primer consisted of one primary set from Veillonella and one universal primary set of $16 \mathrm{~S}$ rDNA.

Table 1. Sequences of Veillonella [13] and 16SrDNA [14] primers.

\begin{tabular}{cll}
\hline \multicolumn{1}{c}{ Bacteria } & \multicolumn{1}{c}{ Primer } & \multicolumn{1}{c}{ Sequence } \\
\hline Veillonella & Veil-rpoBF & GTA ACA AAG GTG TCG TTT CTC G \\
& Veil-rpoBR & GCA CCR TCA AAT ACA GGT GTA GC \\
\multirow{2}{*}{ 16S rDNA } & Total Bakteri-F & ACG TCR TCC MCA CCT TCC TC \\
& Total Bakteri-R & GTG STG CAY GGY TGT CGT CA \\
\hline
\end{tabular}

The appropriate primer was then diluted to obtain a primary stock solution, using TE solution (Tris EDTA), until it reached $100 \mu \mathrm{M}$, depending on each primer. For example, $28.1 \mu \mathrm{M}$ Veil-rpoBF primer needed $281 \mu \mathrm{M}$ TE solution to dilute it. Next, a working solution was prepared based on the number of samples, so the volume of working solution needed for 100 samples was $10 \mu \mathrm{L}$ primer with $90 \mu \mathrm{L}$ nuclease-free water $(\mathrm{NFW})$.

\section{RT-PCR Protocol}

The RT-PCR process was performed using SensiFAST SYBR Hi-ROX Kit (Bioline Reagents Ltd., London, UK) with a standard PCR Master Mix volume of $20 \mu \mathrm{L}$, consisting of $10 \mu \mathrm{L}$ SensiFAST SYBR HiROX, 0.8 $\mu \mathrm{L}$ forward primer, $0.8 \mu \mathrm{L}$ reverse primer, and the sample $(\leq 8.4 \mu \mathrm{L})$, along with NFW added as required. The PCR Master Mix of each sample (23 samples in total) was inserted into a MicroAmp Fast Optical 48-well reaction plate with one duplicate control and covered with MicroAmp Fast 48-well optical adhesive film (Thermo Fisher Scientific, Waltham, MA, USA). RT-PCR was run by inserting the 48-well reaction plate in its plate. For Veillonella spp., 40 cycles were run, whereas 35 cycles were run for $16 \mathrm{~S}$ rDNA. The temperature and the time needed for each cycle should be customized according to which PCR kit is used. In this study, the polymerization activation was set at $95^{\circ} \mathrm{C}$ for 2 minutes, denaturation at $95^{\circ} \mathrm{C}$ for 5 seconds, annealing at $60^{\circ} \mathrm{C}$ for 10 seconds, and extension at $72^{\circ} \mathrm{C}$ for 20 seconds. The final step was to analyze the melting curve for one cycle at $95^{\circ} \mathrm{C}$ for 15 seconds and $60^{\circ} \mathrm{C}$ for 1 minute [15]. After the RT-PCR results were obtained, relative quantification was used to determine relative gene expression changes compared with the reference sample. The $2^{-\Delta \Delta_{\mathrm{CT}}}$ method is a relative quantification method widely used in a software package for RT-PCR testing. This method directly uses threshold cycle information resulting from the RT-PCR system to calculate relative gene expression in targeted and reference samples, using the reference gene as a normalizer. The threshold cycle is a cycle in which the fluorescence level reaches a particular number (threshold) [16].

Quantification of amplified products was performed using fluorescent probes or fluorescent DNAbinding dyes and RT-PCR instruments that measured fluorescence while performing the thermal cycling necessary for the PCR [17].

Data Analysis

Data were analyzed using IBM SPSS Statistics for Windows Software, version 20 (IBM Corp., Armonk, NY, USA). The Mann-Whitney test was used and the level of significance was set at 5\%. 
Ethical Considerations

Ethical permission was granted by the Research Ethics Committee (KEPKG) of the Faculty of Dentistry of the University of Indonesia, with the registered number 75/Ethical Approval/FKGUI/XII/2017. Informed consent was obtained from a child's parents before any examinations were conducted.

\section{Results}

The total number of participants who provided samples for the study was 87 children, aged 2 to 3 years, who came with their mothers to the Integrated Service Post in the work area of the Community Health Center. Of these children, $31 \%$ were aged 2 years and $69 \%$ were aged 3 years; they were examined for dmfs, and saliva samples were taken. Kappa value for inter-examiner agreement for the presence of dental caries was 0.87. Out of the 87 children examined, 62 children were found with caries $(71.3 \%)$, while the mean dmfs was $7.10( \pm 9.05)$.

Thermal cycling (CT) for $16 \mathrm{~S}$ rDNA was, on average, lower than that of Veillonella spp., indicating that total bacteria were identified more rapidly than Veillonella spp. (Table 2).

Table 2. Threshold cycle mean RT-PCR of Veillonella spp. and $16 \mathrm{~S}$ rDNA.

\begin{tabular}{|c|c|c|c|c|c|}
\hline \multirow[b]{2}{*}{ Variables } & \multirow[t]{2}{*}{$\mathbf{N}$} & \multicolumn{2}{|c|}{ Veillonella spp. } & \multicolumn{2}{|c|}{$16 \mathrm{~S}$ rDNA } \\
\hline & & Mean (SD) & p-value & Mean (SD) & p-value \\
\hline Sex & & & $0.044^{*}$ & & 0.259 \\
\hline Boys & 42 & $22.79 \pm 2.84$ & & $14.39 \pm 1.79$ & \\
\hline Girls & 45 & $24.37 \pm 3.83$ & & $14.99 \pm 1.99$ & \\
\hline Age & & & 0.607 & & 0.224 \\
\hline 2 Years & 27 & $23.37 \pm 3.23$ & & $14.33 \pm 1.69$ & \\
\hline 3 Years & 60 & $23.71 \pm 3.57$ & & $14.88 \pm 1.69$ & \\
\hline Dental Caries Status & & & 0.289 & & 0.289 \\
\hline Caries-Free & 25 & $24.44 \pm 3.86$ & & $15.10 \pm 2.06$ & \\
\hline $\mathrm{ECC}$ & 62 & $23.27 \pm 3.25$ & & $14.54 \pm 1.84$ & \\
\hline
\end{tabular}

Mann-Whitney rank sum test; *Statistically Significant.

The average proportion of Veillonella spp. in boys $(2.76 \pm 2.49)$ was lower than that in girls $(3.14 \pm$ 7.89), whereas dmfs in girls was higher than in boys. The proportion of Veillonella spp. differed significantly between the sexes $(\mathrm{p}<0.05)$. The average proportion of Veillonella spp. in children aged 2 years $(1.84 \pm 1.59)$ was lower than that in children aged 3 years $(3.46 \pm 6.99)$, whereas the dmfs in children aged 2 years was lower than in children aged 3 years. The average proportion of Veillonella spp. in children free of caries (2.13 \pm 2.30) was lower than in children with $\operatorname{ECC}(3.29 \pm 6.83)$. The proportion of Veillonella spp. was not significantly different between age and dental caries status ( $\mathrm{p}>0.05)$ (Table 3).

Table 3. Correlation between mean dmfs, proportion of Veillonella spp., sex, age, and dental caries status.

\begin{tabular}{|c|c|c|c|}
\hline \multirow[b]{2}{*}{ Variables } & \multirow{2}{*}{$\begin{array}{c}\text { dmfs } \\
\text { Mean (SD) }\end{array}$} & \multicolumn{2}{|c|}{ Proportion of Veillonella spp. } \\
\hline & & Mean $(\mathrm{SD})$ & p-value \\
\hline Sex & & & $0.022^{*}$ \\
\hline Boys & $6.90 \pm 9.18$ & $2.76 \pm 2.49$ & \\
\hline Girls & $7.29 \pm 9.03$ & $3.14 \pm 7.89$ & \\
\hline Age & & & 0.749 \\
\hline 2 Years & $4.19 \pm 8.80$ & $1.84 \pm 1.59$ & \\
\hline 3 Years & $8.42 \pm 8.93$ & $3.46 \pm 6.99$ & \\
\hline
\end{tabular}




\begin{tabular}{lccc}
$\begin{array}{l}\text { Dental Caries Status } \\
\text { Caries-Free }\end{array}$ & & & 0.750 \\
ECC & 0 & $2.13 \pm 2.30$ & \\
\hline Mann-Whitney rank sum test; *Statistically Significant. & $3.29 \pm 6.83$ &
\end{tabular}

\section{Discussion}

Dental caries is one of the most prevalent oral infectious diseases worldwide, which requires expensive treatment. The prevalence of caries in the primary dentition underlies the importance of its prediction and prevention. Furthermore, early childhood caries (ECC) has become a prevalent public health problem among preschool children worldwide. However, little is known about the microbial community involved in ECC.

The detection of specific bacteria associated with ECC can facilitate the prevention and treatment of dental caries in young children [18]. When DNA from samples of dental caries was directly sequenced, obviating cloning or PCR techniques, Veillonella was found to be the most common genus, underlining the varying nature of microbial composition in cavities. However, these DNA-based studies may quantify dead, transient, or inactive microorganisms that do not contribute to disease, inflating estimates of diversity and introducing noise to the analysis [19].

Early colonizers, such as S. mutans and Veillonella spp., and bridging species, such as fusobacteria, join the community through interactions with pioneer colonizers or by adhering to available sites on the tooth surface. Growth of the early colonizers then modifies the local environment, rendering it favorable for the growth of late colonizers, which mostly consist of gram-negative, obligate anaerobic bacteria [20].

Veillonella are also early colonizers of the oral biofilm and are one of the most prevalent colonizers of the human oral cavity. A common characteristic of this genus is that they do not utilize carbohydrates; rather, they metabolize lactate, pyruvate, and peptones to produce propionate and acetate. This nutritional requirement makes them dependent upon streptococci, which excrete lactate as a waste product of carbohydrate fermentation. Of particular interest in this Veillonella-streptococci association is the removal of lactic acid by Veillonella. Lactic acid produced by streptococci is primarily responsible for the characteristic demineralization found in dental caries, which raises an interesting question as to the role of Veillonella in cariogenesis [20].

Early studies using gnotobiotic rats found reduced caries activity and tooth demineralization caused by $S$. mutans when it was co-inoculated with Veillonella spp.; however, recent epidemiological studies in humans have found high numbers of veillonellae associated with high numbers of $S$. mutans in carious lesions [21].

\section{Conclusion}

The proportion of Veillonella spp. in children with ECC was higher than caries-free children, so Veillonella spp. may be a risk factor for ECC.

\section{Authors' Contributions}

\begin{tabular}{|c|c|c|}
\hline ASS & (D) $0000-0001-5628-4055$ & $\begin{array}{l}\text { Conceptualization, Investigation, Writing - Original Draft Preparation and } \\
\text { Writing - Review and Editing. }\end{array}$ \\
\hline RRD & (D) $0000-0001-7480-7876$ & Investigation and Writing - Review and Editing. \\
\hline SS & (D) 0000-0003-1004-2055 & Investigation and Writing - Review and Editing. \\
\hline DAM & (iD) $0000-0001-6713-786 \mathrm{X}$ & Investigation and Writing - Review and Editing. \\
\hline AAD & (D) $0000-0001-5667-9444$ & Methodology, Writing - Review and Editing and Supervision. \\
\hline
\end{tabular}




\section{Financial Support}

Directorate Research and Community Engagement Universitas of Indonesia (Grant No. NKB0134/UN2.R3.1/HKP.05.00/2019).

\section{Conflict of Interest}

The authors declare no conflicts of interest.

\section{References}

[1] Hajishengallis E, Parsaei Y, Klein MI, Koo H. Advances in the microbial etiology and pathgenesis of early childhood caries. Mol Oral Microbiol 2017; 32(1):24-34. https://doi.org/10.1111/omi.12152

[2] Law V, Seow WK, Townsend G. Factors influencing oral colonization of mutans streptococci in young children. Aust Dent J 2007; 52(2):93-100. https://doi.org/10.1111/j.1834-7819.2007.tb00471.x

[3] Wan AKL, Seow WK, Walsh LJ, Bird PS. Comparison od five selective media for the growth and enumeration of Streptococcus mutans. Aust Dent J 2002; 47(1):21-6. https://doi.org/10.1111/j.1834-7819.2002.tbo0298.x

[4] Aas JA, Griffen AL, Dardis SR, Lee AM, Olsen I, Dewhirst FE, et al. Bacteria of dental caries in primary and permanent teeth in children and young adults. J clin Microbiol 2008; 46(4):1407-17. https://doi.org/10.1128/JCM.01410-07

[5] Xu H, Hao W, Zhou Q, Wang W, Xia Z, Liu C, et al. Plaque bacterial microbiome diversity in children younger than 30 months with or without caries prior to eruption of second primary molars. PLos One 2014; 9(2):e89269. https://doi.org/10.1371/journal.pone.0089269

[6] Parisotto TM, Steiner-Oliveira C, Silva CM, Rodrigues LK, Nobre-dos-Santos M. Early childhood caries and mutans streptococci: a systematic review. Oral Health Prev Dent 2010; 8(1):59-70. https://doi.org/10.3290/j.ohpd.a18828

[7] Fung MHT, Wong MCM, Lo ECM, Chu CH. Early childhood caries: a literature review. J Oral Hyg Health 2013; 1(1):107. https://doi.org/10.4172/2332-0702.1000107

[8] Mashima I, Theodorea CF, Thaweboon B, Thaweboon S, Scannapieco FA, Nakazawa F. Exploring the salivary microbiome of children stratified by the Oral Hygiene Index. PLoS One 2017; 12(9):e0185274. https://doi.org/10.1371/journal.pone.0185274

[9] Koning JW. Interactions between Streptococcus mutans and Veillonella dispar. [Thesis]. London: University College London; 2010.

[10] Becker MR, Paster BJ, Leys EJ, Moeschberger ML, Kenyon SG, Galvin JL, et al. Molecular analysis of bacterial species associated with childhood caries. J Clin Microbiol 2002; 4O(3):1001-9. https://doi.org/10.1 128/jcm.40.3.10011009.2002

[11] World Health Organization. Oral Health Surveys: Basic Methods. 5th ed. Geneva: WHO; 2013.

[12] Zhang S, Liu J, Lo ECM, Chu C. Dental caries status of Bulang preschool children in Southwest China. BMC Oral Health 2014; 14:16. https://doi.org/10.1186/1472-6831-14-16

[13] Arif N, Sheehy EC, Do T, Beighton D. Diversity of Veillonella spp. from sound and carious sites in children. J Dent Res 2008; 87(3):278-82. https://doi.org/10.1177/154405910808700308

[14] Maeda H, Fujimoto C, Haruki Y, Maeda T, Kokeguchi S, Petelin M, et al. Quantitative real-time PCR using TaqMan and SYBR Green for Actinobacillus actinomycetemcomitans, Porphyromonas gingivalis, Prevotella intermedia, tetQ gene and total bacteria. FEMS Immunol Med Microbiol 2003; 39(1):81-6. https://doi.org/10.1016/So9288244(03)00224-4

[15] Childers NK, Osgood RC, Hsu KL, Manmontri C, Momeni SS, Mahtani HK, et al. Real-time quantitative polymerase chain reaction for enumeration of Streptococcus mutans from oral sample. Eur J Oral Sci 2011; 119(6):447-54. https://doi.org/10.1111/j.1600-0722.2011.00888.x

[16] Rao X, Huang X, Zhou Z, Lin X. An improvement of the $2^{\wedge}$ (-delta delta CT) method for quantitative real-time polymerase chain reaction data analysis. Biostat Bioinforma Biomath 2013; 3(3):71-85.

[17] Life Technologies. Thermo Fisher Scientific Inc. Real-time PCR Handbook. 2012. Available from: https://www.thermofisher.com/content/dam/LifeTech/global/Forms/PDF/real-time-pcr-handbook.pdf. [Accessed on 14 January 2020].

[18] Ma C, Chen F, Zhang Y, Sun X, Tong P, Si Y, et al. Comparison of oral microbial profiles between children with severe early childhood caries and caries-free children using the human oral microbe identification microarray. PLoS One 2015; 10(3):e0122075. https://doi.org/10.1371/journal.pone.0122075

[19] Simón-Soro A, Mira A. Solving the etiology of dental caries. Trends Microbiol 2015; 23(2):76-82. https://doi.org/10.1016/j.tim.2014.10.010

[20] Liu J, Wu C, Huang IH, Merritt J, Qi F. Differential response of Streptococcus mutans towards friend and foe in mixed-species cultures. Microbiology 2011;157(9):2433-44. https://doi.org/10.1099/mic.0.048314-0 
[21] Aas JA, Paster BJ, Stokes LN, Olsen I, Dewhirst FE. Defining the normal bacterial flora of the oral cavity. J Clin Microbiol 2005; 43(11):572 1-32. https://doi.org/10.1 128/JCM.43.11.5721-5732.2005 